\title{
A TRUSTEE IN A WORLD OF CHANGING VALUES
}

\author{
Louis S. HEADLEY*
}

Trustees have been confronted in recent years with a multitude of novel problems. Personal property has come into the ascendancy. The use of the corporate structure has added greatly to the forms of securities to be administered. It has made frequent the investment of funds in unfamiliar and far-away enterprises. It has raised difficult problems of accounting. Reorganizations and consolidations, rights to subscribe to additional stock, realization upon collateral under bond indentures, these and numerous other problems have added to the responsibilities of trustees. Taxes have in creased in kinds and complications. Government regulations have imposed new burdens. In the administrative field alone the duties of a trustee have greatly increased.

Numerous and burdensome, however, as these added duties are, they do not compare in their importance or difficulty with the ancient and fundamental problem underlying all trusteeship, that of the preservation of values in a changing world. A trustee is a conservator and not a creator of wealth. He conserves wealth and eventually distributes it according to the plan, and to effect the purposes, of another. How best to preserve and administer values so as to accomplish the designs of the settlor is the changeless function of a trustee.

It is impossible to approach this problem without surveying the nature of value, the forms which it takes, the purposes behind its accumulation and the political and economic media in which a trustee must function today.

Wealth comes from the dust, and to dust all wealth eventually returns. Value is a transient attribute. Things become property when they are reduced to possession. Possessions become valuable when they satisfy human wants. Values disappear when possessions no longer satisfy; and possessions cease to be property when they are abandoned and, through rust and decay, return to their native state. Thus there is a material vortex into which an infinitesimal part of earth's substance is drawn, and that rapidly gyrating vortex of matter constitutes the wealth of society.

The composition of this spiral is continually changing. New inventions, new discoveries and constructions are perpetually sweeping new particles into the whirlpool. Some bits are stirred into life for a moment. They rustle for a day and then revert to their eternal sleep. These are the lost enterprises. They have missed the

- B.S., 1907, Carleton College; LL.B., I912, Harvard University. Member of the New York and Minnesota Bars. Vice-President, First Trust Company of Saint Paul. Executive Committee, Trust Division, American Bankers Association. 
great movement. Others reach the very center of activity. They are carried along for years and become the useful and valuable property of the world. They are infinite in variety-a Chinese junk on the Hoang-ho, a clipper ship over the Pacific, a jewel on a lady's finger, things without end-and they are valuable because they all satisfy some human desire.

But disintegration eventually comes. Things grow old, fashions change, new devices supplant outmoded ones. What was valuable today may be worthless tomorrow. All property is eventually lost. It gravitates toward the receding side of the vortex, passes out and is gone. Matter persists but values disappear.

When the mass of useful property is large society prospers and standards of living are high. When the movement is retarded we all suffer. If the round of production and consumption is kept active it makes little difference to society as a whole who produces and who consumes. It is unimportant to the wool-grower whether his product provides fifty suits for a society swell or hundreds of stockings for poor children. A like amount is produced and consumed. Herein is the philosophy of waste. The important thing is to keep the process in active operation.

The products of industry are used in two ways. Some are consumed in the using. They satisfy immediate wants. Others are thrown back into the vortex and produce more property to satisfy other wants. If, through want of restraint, too much is consumed the productive whirl slows down and want ensues. If, because of faulty distribution, too little is consumed the spiral clogs with like results. Economy requires that production shall keep pace with consumption, and that consumption, whether of one kind or the other, shall keep pace with production. The vortex must be kept spinning.

While it may be of little concern to society as a whole who produces and who consumes, it makes a vast deal of difference to the individuals who make up that society. In our economic philosophy the individual is the unit and not the state. Each individual seeks to share as generously as he can in the consumptive process; and to obtain that participation he labors to possess an ownership in the vortex of valuable things. That is the problem of accumulation.

But temporary possession is not enough. A man's life ordinarily is longer than his active years. Beyond that his dependents may live through another generation. It is important to him and to them that the things which he has acquired remain in the vortex of valuable property. That is the problem of investment.

The accumulation of wealth, and its preservation, are distinct functions often requiring distinct and different techniques. The industrialist is engaged primarily in the former. The trustee is concerned almost entirely with the latter. It is his function to conserve and not to produce.

We have already observed that all wealth is ultimately attributable to things, and that if things are to remain valuable they must be kept in the vortex of useful property. Basically this is the problem of all investment. It is obvious that the same things cannot be retained forever for they are in constant flux. The successful 
investor must see to it that things which are on their way out of the vortex are exchanged in time for things which are on their way in. Someone must take the loss but not he. He must keep in the swim by shrewd barter, or by using a part of a productive but deteriorating property to acquire other property whose usefulness is only commencing. If his property is in consumptive goods he must dispose of them before they are outmoded or decayed. Even ownership in real estate must be kept in the direction of a city's growth.

These considerations are important whether ownership is directly in things or in the evidence of things such as stock in a corporation. An investor in stocks must see to it that his corporation owns useful property and is engaged in constantly useful production, that it makes adequate provision for deterioration and obsolescence, that its management is alert to changing conditions. All of this requires skill and ingenuity of a high order. There is no assurance even in the ownership of tangible things, whether direct or through a corporation, that values will persist. All is change. Things disappear and values pass away. Sic transit gloria mundi!

So far we have said nothing about money. We have purposely omitted any reference to it in order to emphasize that real wealth consists in things and not in a medium for their exchange. But having underscored what may be obvious let us now turn to other considerations.

It is unnecessary to trace at any length the familiar story of how certain articles, chiefly the precious metals which were durable, divisible and of intrinsic and concentrated worth, came naturally to be used as money. They were universally sought after, everyone knowing that they could be traded in turn for other things, at other times, and at other places. They served in three ways, as a medium of exchange, as a measure of value, and as a storehouse for wealth. These separate functions of money require brief attention.

There are between one and a half and two billion people living on this planet. The great majority of them are concerned with the economic process. All are striving for the present and future satisfaction of wants. Comparatively few of them are self-sufficient, and those few live a meager existence. Most of them want to share in the things which others produce. One who makes shoes cannot live on shoes. He must trade them for other things. But to convert shoes into food and drink and a thousand other articles from remote or near-by places requires the interposition of a medium of exchange. To serve in that capacity is one of the commonest functions of money.

A second function of money, closely related to the first, is to provide a measure of value. What an undertaking this is! We have already noted the unstable nature of value, changing with customs and tastes, being relative to all desirable things, and fluctuating with the law of supply and demand. And yet if things are to be exchanged it is highly desirable if not imperative that some standard of value be established by' relation to which the value of all other things can be measured. A standard suggests uniformity, something fixed and stable. If the standard remains 
the same planning is possible. Things may change in value but not because of a change in the unit by which their values are measured. Without a standard we revert to barter.

Where can a standard of value be found? For an answer we must consult experience. Then we find that no other thing in ancient or modern times has so closely approximated the ultimate desideratum as gold. The reason why gold has been used is inherent and not arbitrary. The quantity does not change greatly from age to age. Such increase as occurs is largely compensated by greater demand. It is in itself a useful metal. From earliest times it has appealed to mankind as something to be desired. Until recently, at least, the greater part of mankind has been content to relate all economic values to gold.

We must recognize, however, that even gold is not an entirely satisfactory measure of worth. Despite the comparative uniformity in the world's supply of monetary gold there have been times when the amount has greatly increased. The discovery of new mines or improved processes of refining have more than off-set increased consumption in the arts. Since the discovery of America the world supply has increased perhaps 150 times. While increased demand has compensated in part for the increased supply such increase in prices as has occurred is due at least in part to the increased supply of gold. In an attempt to maintain a uniform standard governments have arbitrarily fixed and maintained the price of gold in relation to their currency units. For a century $£_{3} \mathrm{I}$ s. 10 $1 / 2 d$. and an ounce of gold were one and the same thing. We must recognize, however, that no single commodity, not even gold, is a perfect measure of value.

Professor Fisher has urged for a lifetime that a more equitable and useful measure is the composite value of many commodities in daily demand. But the difficulty of selecting representative goods and giving them their proper weight, and the practical problems of administration thus far have prevented the adoption of a commodity dollar. Whatever its form it seems probable that money will always remain a more or less variable measure of value.

The third function of money to which we have adverted is to serve as a reservoir of wealth. We come closer at this point to the problem of the investor. Can values be preserved in the form of money? We observed at the outset that to preserve values once created one must maintain an ownership or interest in useful things. We spoke of ownership as direct, or as indirect through the medium of corporate stock. The problems were basically much the same. We have now to deal with interests in property which are not ownership but are evidenced by obligations payable in money.

One who has traded his tangible assets for money, and has loaned it to another, must see to it that the money which he has loaned is invested and kept invested in property in the productive vortex, or that his debtor has other property from which he can repay the sum borrowed. The creditor must be able to realize the amount of his loan before the assets of his debtor pass beyond the penumbra of value. 
But that is not all. One who measures his wealth in money or in money obligations has an additional problem quite as difficult as that of the owner of tangible assets. He knows the present value of money, but can he know that it will continue valuable? Wholly apart from the ability of his debtor to pay, will the payments at a later date be worth what they are today?

As long as money is gold or convertible into gold at a fixed amount creditors have felt reasonably safe. While recognizing that even gold may fluctuate in its purchasing power it has seemed to them the most stable reservoir available. After the legal tender cases in the Eighteen-Seventies it was customary to require that long-time debts be payable in gold dollars of an established weight and fineness. But governments have power to regulate the value of money. Britain finally went off the gold standard in 1931. This country followed in 1933. The gold clauses in contracts were abrogated. Dollars were no longer convertible into gold. Moreover, by increasing the price which our government was willing to pay for gold the dollar was cheapened in terms of gold and was eventually devalued to $59.06 \%$ of its former worth. It was allowed to seek its own level. In foreign trade the result was an immediate and precipitate decline in purchasing power, although through the use of the stabilization fund a certain parity was maintained with other currencies. At home the immediate effect upon prices was slight. All transactions were merely transferred to another level with relation to gold, but as gold payments were abrogated it had little immediate effect upon prices. However, the inevitable tendency of setting the dollar adrift is to lessen its purchasing power both at home and abroad. The money reservoir of value has sprung a serious leak.

The danger of inflation, which may be broadly defined as the "condition arising when purchasing power is made available to the public at a faster rate than goods are made and brought to market". is not, however, limited to inflation of the currency. Purchasing power does not depend so much upon the amount of currency as upon the amount of credit available. Bank deposits are money in an economic sense as truly as legal tender. Over $95 \%$ of the nation's business is transacted by checks. Behind these checks, for the most part, are deposits created by credit loans to customers, and behind the loans are various forms of collateral. These credit loans are susceptible of very great expansion. This is particularly true when the loans are to government and the collateral is merely the promise of government to pay in the form of government bonds. Thus the great increase in the national debt, financed largely through loans from banks, has vastly extended the credit structure of the country and laid the foundation for further inflation. The money borrowed has been pumped into circulation by generous loans and grants, without, however, materially increasing our national wealth. A multitude of counter tendencies and control measures, and the lack of confidence in the situation, have thus far kept inflation in check, but the expansion of the basis for credit has made possible a great increase in bank money which may result in a serious cheapening of the dollar.

From this necessarily cursory review of the situation we must conclude that 
money is never a sure repository for wealth, and that it is a particularly uncertain one today. The danger is a matter of degree. It may become great, and it may not. The expectation that values can ever be maintained at a precise level is beyond reason. It has never been possible in the past. It seems unlikely that it will be completely possible in the future. From the close of the Napoleonic Wars to 1896 the English pound more than doubled in its purchasing power. From the close of the Civil War to the same date the American dollar more than trebled. The owner of fixed obligations was then the unwitting benefactor. Debtors were the losers. A change came, however, with the close of the century. By r922, with the World War intervening, the pound had fallen to its level in 1815. In this country the dollar was worth less than half its value in 1865 . The low of 1920 , however, was of short duration. By 1933 the purchasing power of the dollar was $26 \%$ larger than in 1913 and $75 \%$ larger than in 1929 . As a compromise President Roosevelt has sought to bring commodities back to their value in 1926. It is an arbitrary point. History discloses no fixed and continuing value for money. Despite all of this people generally have continued to accept money obligations as the surest repositories for wealth among the vicissitudes of time.

It may be fair to ask whether an investor searching for permanent values is expecting too much. When everything else is changing does justice require that money alone shall remain at par? In a highly competitive and individualistic society, left open to the play of natural forces, who can say that injustice is done if a relation which prevailed at one time is not maintained at another? It is a variable with which the capable individual must reckon. We have an intuitive feeling of unfairness if relative values change too rapidly or from artificial causes; we have far less abhorrence if the change is gradual and natural. We think it unjust that an individual who has labored through the heat of mid-life should find his values gone in old age; we are little disturbed if the second or third generation finds the dollar depreciated. After all, the test is largely pragmatic. We want a money which will encourage a stable and progressive society. If it is commonly understood that money is unstable its usefulness is diminished. Trade is seriously hampered; the standard of value disappears; money is spent rather than saved. On the other hand a reasonable assurance that the purchasing power of money will not materially change from decade to decade encourages thrift and the accumulation of capital. People provide for old age and for their dependents. Therefore, while individuals may have no natural right to a permanent level for money, the good of a growing society demands that change shall not be extreme, arbitrary or abrupt.

We have intended to indicate by the foregoing discussion the practical difficulty of preserving values in a dynamic world. The difficulty is inherent in the very nature of temporal things and mortal men. We have spoken of money as a storehouse of wealth. Its strength, we have observed, is in the changeless nature of the obligation and in the tangible property which ordinarily is behind it. Its weakness is its tendency to fluctuate in relation to the commodities which it is intended to 
command. When gold, although stamped into currency, is essentially a commodity, its fluctuation in value is less than that of other commodities. It is for this reason, primarily, that it has been used as money. But when money is not gold or related to gold, when it becomes the fiat of government, when credit can be expanded on the basis of inconvertible commodities, when it becomes the tool of social reformers, when its volume, and to a degree its value, can be increased or decreased almost at will, its usefulness as a permanent repository of wealth is seriously impaired.

The attention of the investing public in recent years has been directed with renewed anxiety to the danger to money obligations from inflation. Its importance has been emphasized by the experience of other countries and by existing conditions and social movements in our own. Without necessarily contemplating a repetition of the German experience we -must recognize that inflation to any degree will lessen the purchasing power of money. If the dollar is reduced to its value in 1926 and held there the damage will be considerable but not serious. It may be that justice requires a return to a somewhat lower level. If the movement gets out of hand the consequences to creditors may prove disastrous. The probabilities must be weighed and a course of action adopted which seems appropriate in the anticipated situation.

It hardly need be pointed out that the problem of inflation is of peculiar concern to beneficiaries of trusts. While tangible assets in various forms are often present it is nevertheless true that by far the greater part of the trust assets in this country is in the form of dollar obligations. The laws of a majority of the states require that such funds shall be invested in no other way. Although trust instruments frequently give wide investment latitude to the trustee, the purposes of the trust and the security of the principal have most often. led to the purchase of bonds. Anything, therefore, which threatens the value of the dollar creates a special problem for the parties to a trust.

How then shall a trustee proceed in the face of possible inflation? It is to this question that our discussion must now be limited. Two things at once suggest themselves. The first is flight-flight from a depreciating currency. But where shall he flee? It may be to other currencies, yet with no currency safely anchored to gold and with the great nations of the world engaged in a currency war, each scheming to cheapen its money below that of the others, this offers little protection.

Or he may seek security in commodities, wheat, copper, petroleum and the like, which continue useful regardless of the value of money. This return to first principles of value has merit, but it involves dangers of a different nature, dangers of shifting values in response to supply and demand, dangers of deterioration or loss, expense of management. Moreover, the requirements of the trust ordinarily cannot be met. A life tenant is looking for income and there is no income from commodities held in storage. An individual may live on capital gains; or if no gains result from the venture he may sustain himself for a time from principal; at a later time if fortune turns he may recoup principal from surplus income. He is not bound by trust instruments or court decisions, or by the relative interests of the present and 
the future. With a trustee. it is quite otherwise. A close accounting must be had between two interests. The rights of the present and the future must be separately maintained. A trustee must measure his authority by the trust instrument, by statutes and by case law. He is limited on many sides. The trustee who buys commodities leaps from one danger to a host of others.

Or, if his authority permits, a trustee may fly to land and endeavor to wrest from it an income. The results, however, cannot be certain. If he buys urban real estate, mounting taxes and expenses of operation may be more than the rents; he may be limited in his charges by law. If he buys farm property he is likely to experience the difficulties which have plagued farmers for the past eighteen years. No, flight, whether to foreign currencies or to commodities or land, has led to no safe haven for the trustee.

The second course of action starts in the same direction but eventually diverges. It contemplates an ultimate return to dollars but in increased numbers. Decreased purchasing power is to be compensated by more dollars. The increase is to come not through production but from a rise in the market. The suggested medium for the speculation is common stocks. Corporate shares largely represent tangible property and earning power. On the other hand they are dealt in apart from the property and ordinarily can be converted more easily into cash. Thus in theory they give the protection of tangible property coupled with an earning power which keeps pace with inflation, but can be changed into dollars when the top of the inflationary movement has been reached. If the speculation has been successful the number of dollars will have been increased to compensate for a loss in their purchasing power.

Were the sequence sure this course would have much to commend it. But how certain is the speculation? If a corporation is operating at a loss its losses are increased by inflation. Multiple regulations and mounting taxes are keeping corporations from accustomed profits. It seems improbable that Congress would allow equity owners to keep the unearned increment which might result from inflation. The problem of management becomes an important factor. Even the German experience is not altogether reassuring. Dr. W. S. Landis, who made a study of the post-war experience there, says, "The mortality of business at this period was perfectly enormous,"1 and concludes his report with this quite unexpected paragraph: "The situation with respect to fixed interest bearing obligations looks quite distressing on the face of it, but in conversation with German bankers they told me that as a whole a large portfolio of bonds ... probably showed a better average liquidating value at the end of the inflation than a similar large portfolio of common stocks." Among purchasers of stocks "only the nimblest speculators," in the words of Walter Lippmann, were successful. While a trust portfolio may often properly contain common stocks of investment quality, the purchase of stocks by a trustee as a hedge against inflation is a doubtful and dangerous procedure.

\footnotetext{
I Landis, AN Engineer Looks at Inflation (Duke Endowment, 1933) i8.
}

2Id. at 27 . 
But should he make the experiment? Should a trustee of dollar obligations attempt to maintain the purchasing power of his trust? Is he under moral or legal obligation to do so? This brings us close to the heart of our problem, for if he is then there is no other course but to feel his way along the paths already indicated; if he is not then the parties may discover other less dangerous ways to accomplish the main purposes of the settlor of his trust.

For our answer to these questions we must look in three places, in the fundamental nature of the trust relationship, in the desires and purposes of those who leave their property in trust, and in the books of decided cases.

A trustee is defined as one "to whom property or funds have been committed in the belief and trust that he will hold and apply the same for the benefit of those who are entitled" thereto. He is the conservator and not the creator of corpus. But what is the nature of the corpus which he is expected to conserve? Two conceptions which have emerged have been described by Nathan Isaacs of the Harvard School of Business Administration as the Res and the Quantum Theories. ${ }^{3}$ The Res Theory conceives of corpus as a thing. It may be land or commodities, or shares of stock, or even bonds. Their value may go up or down in terms of dollars or purchasing power. The trust may profit from an unearned increment or its value may be impaired or entirely destroyed. These changes do not enter into the accounting of the trustee. The corpus has been preserved.

The Quantum Theory is quite different. It speaks of values and not of things. A settlor who creates a trust ordinarily thinks in terms of dollars and not of the particular securities deposited. If the trust is worth $\$ 100,000$ at the outset he expects that it will remain a hundred thousand "dollars." The remainderman, too, expects to receive $\$ 100,000$ worth of securities at the end rather than the particular securities with which the trust started. It is little consolation to one who is handed a seriously impaired stock or bond to be told that it is the very security received from the settlor. On this theory the principal to be preserved is a value and not a thing. It is a quantum and not a res.

While there has been a curious inconsistency in the adherence to either of these theories in trust accounting, for most purposes the quantum theory is in the clear ascendancy. Ordinarily a trustee has been considered blameless if he has maintained the dollar value of his trust and blameworthy if he has not.

It may be suggested that it is but an extension of the quantum theory to require a trustee to maintain a value measured in terms of purchasing power rather than of the monetary unit. Let us see what this means. Obviously it is impossible to maintain the purchasing power of the dollar during inflation. By definition a stable dollar and an inflated currency are mutually exclusive. It is the purchasing power of a fund and not of the dollar that is to be maintained. If values are to be reckoned in dollars it means that the number of dollars must be increased. This is done by converting dollars into tangibles or the evidence of tangible things, holding them until

\footnotetext{
'Isaacs, Principal-Quantum or Res? (1933) 46 HARv. L. Rev. 776.
} 
dollars have cheapened, and by then exchanging them for more dollars. This is speculation in dollars. Of if purchasing power is not to be measured in dollars we must resort to a yardstick which represents a relation in value between a particular thing and a composite of all other desirable things. Obviously this would be a variable norm and impossible of exact determination. A commodity dollar representing a composite of a few standard commodities properly weighted would be a rough approximation, but only an approximation, to a true unit of relative values. It would represent the barter value of a thing in relation to a few others. It would probably have to serve as the unit for accounting purposes, for without some unit no accounting would be possible. Thus far the business world has accepted no such unit. Unless, then, we are to assume that trusteeship requires a trustee to shift from dollars into things and to hold them on the res theory, rendering his accounts in terms of a theoretical and non-existent unit of value, we are forced to conclude that a trustee has no duty to attempt to maintain the purchasing power of his trust.

But perhaps a more realistic approach to our problem can be found in the essential purposes and wishes of the average settlor. These, of course, are the ultimate criteria. Why does a person acquire property and leave it in trust for others? The motives which lead to the acquisition of property are numeraus. At the outset the chief motive is to provide for the physical necessities and comforts of himself and family. Beyond that it is the acquisition of power and the joy of the game. But the pleasure of acquisition cannot be transmitted to posterity, and the power of an heir is limited when his property is placed in trust. Trusts are created primarily to provide for the sustenance and comfort of immediate dependents. With remote remaindermen a settlor is little concerned. He wants protection for his wife and children. Anyone who has dealt with testators knows how security for these immediate members of the family looms as the dominant and overwhelming consideration. Ordinarily he wants the entire income at their disposal; if that is not enough he wants the trustee to use the principal; principal acquired during lifetime is often buttressed by insurance. He wants to provide a backlog for those for whom he is responsible. He does not want to risk the safety of life tenants to provide an inheritance for remaindermen. He does not want speculation, even in dollars, if we can judge from the investment provisions of most wills. Although the dollar has fluctuated widely in the past, and although the possibility of inflation is well known today, there has been virtually no direction on the part of testators to attempt to protect against it. Apparently they have preferred to make other provisions for their beneficiaries, or even to contemplate for them a reduced standard of living rather than to expose them to the undoubted dangers of dollar speculation.

The third direction in which we can look for an answer is to the decided cases. Is there anything in the books which requires a trustee to maintain a value for his trust in relation to something other than money? Nothing whatever. There seems to be no case where a trustee has ever been surcharged merely because the purchasing power of his trust had diminished due to a change in the value of the dollar. On the 
other hand the duties of a trustee have frequently been set down in broad but specific terms. A trustee must eschew "all investments for an uncertain and doubtful rise in the market." He must provide an income for the life tenant which is both "reasonable and regular"; and he must so invest the fund "as to preserve its value."

Speculation is defined as "buying and selling, not in the ordinary course of commerce for the continuous marketing of commodities, but to hold in the expectation of selling at a profit upon a change in values or market rates." The purchase of commodities or common stocks to be held for a market rise, even though the expected rise is to come from inflation, certainly is a speculation, denounced by the first principles of trusteeship.

Nor can "reasonable and regular" income be assured by the practice. Commodities held for a profit produce no income; the returns from real estate are uncertain; while dividends on certain stocks have become fairly regular this is merely by custom and not by agreement. Practically they stop before interest. By any of these methods the reasonableness and regularity of income is sacrificed for an anticipated but uncertain appreciation in principal.

But what of maintaining "value"? If value is measured in dollars inflation creates no problem. But if "value" means purchasing power a trustee is clearly on the horns of a dilemma. Either he must speculate in dollars and violate the first and second principles, or he must keep the dollars he has and violate the third.

We come to the conclusion, therefore, by three approaches that a-trustee has no duty to attempt to maintain the purchasing power of his trust. Through some of the suggested courses an individual who can take the chances may succeed. In the German experience Dr. Landis remarks that "there were a few lucky speculators who held their capital through the inflation by switch and lucky guesses, but the number is almost infinitesimal." "The dollar may fluctuate widely in America, and there may be some speculators who will profit by switches and lucky guesses, but such a course is not open to the ordinary trustee.

Of course, it is always within the power of one planning a trust to give specific instructions. He may go the full length of directing his trustee to adopt the usual hedges against inflation. Whether a responsible trustee will be willing to undertake the task is for him to decide. If the direction to buy common stocks for a market rise is clear and if a trustee embarks upon the program he will invest ordinarily in companies which are not heavily in debt, which are conservatively managed, which have large stores of raw materials, where the cost of production will not mount as fast as the dollar depreciates, and where the price of the commodity can easily and rapidly be changed.

If stocks are to be bought diversification becomes of the greatest importance. Some stocks do well during inflation while others do very badly. In theory a well diversified list of stocks managed through an experienced and successful investment trust has many' advantages. It will never be safe to specialize in a single stock.

'Landis, op. cit. supra note $I$, at 21. 
But even within the framework of conservative trusteeship there are some things which a settlor and his trustee can do better to insure the accomplishment of the essential purposes which the settlor has in mind. Let us come to some positive suggestions.

We have spoken of the theoretical usefulness of a commodity dollar. A settlor may create a commodity dollar of his own. A beneficiary whose income is related to a commodity index will not suffer as a result of inflation. If the index goes to 125 or 150 in relation to an established par his dollar income will be augmented to the extent of $25 \%$ or $33 \frac{1}{3} \%$. Its purchasing power will remain the same. On the other hand if the index falls below par the beneficiary will not profit and the principal will be recouped. It is possible for a settlor to provide that remittances to his beneficiaries shall vary with the cost of living as measured by some commodity index rather than be limited to income. The plan has much to commend it. It would reasonably insure the comfort of the first objects of his bounty. Remittances in excess of income, of course, would come from principal. If inflation was moderate the impairment would not be great; if it became cataclysmic no device would avail.

If a testator does not care to be as precise as the foregoing would require he can give his trustee broad power to invade principal for the benefit of life tenants as the situation from time to time may demand. Inflation is not the only thing which may affect the needs of a wife or children. Sickness may come, children may need to be educated, income may dwindle, circumstances may change in many ways, each making income insufficient for necessary expenditures. For all of these the trustee should have power to provide. An independent judgment which can pass upon the merits of current demands should be lodged in the person of the trustee. What matter if the principal is reduced? The trustee can see to it better than the decedent that the fund serves its purpose to the best advantage. If the fund is seriously reduced or even entirely consumed it will probably more nearly have served its purpose than as though life tenants had been allowed to suffer privation to preserve a principal for distant and unknown remaindermen.

It may be wise for a testator to authorize his trustee to buy a home for dependents, if one is not already provided, and to hold it as a part of the trust. This seems to be a sensible way of assuring one of the first and most important requirements of a beneficiary.

There is something to be said for making it possible for a trustee to set up a beneficiary in a small business of a personal service nature, involving but a small investment of capital, where the overhead would be light, and the charge could be rapidly changed.

Trustees as a body are allied with all others who are interested in maintaining the purchasing power of accumulated wealth and should be active in teaching the social importance of a sound currency. But aside from the few simple devices which have been suggested there seems to be little that a conservative individual or his trustee can do in the face of possible inflation. To some this will sound like defeat- 
ism. They will charge cowardice and inefficiency. To others I trust it will sound like common sense. Trusteeship has its limitations. Conservatism is one of them. But conservatism may also prove to be a tower of strength. A settlor planning for the long future must make his choice and accept the consequences for good or for ill.

The problem of a fluctuating value for money is one calling for the consideration of both settlor and trustee. Neither can deal satisfactorily with it alone. Unless a settlor indicates in advance a course which he wants his trustee to take with respect to inflation, and clothes him with powers adequate for its pursuance, there is little a trustee can do. He must assume that the settlor has intended an administration according to long established principles. Unless a trustee is granted full immunity he cannot safely depart from the requirements of decided cases. He cannot adopt a course of his own choosing.

Whether the immediate prospect is one which justifies letting go the pilot of experience in the investment of trust funds is at least doubtful. There is danger of becoming seized with panic at the first mention of inflation. The story of the assignat and the mark is a gloomy one, but our economic condition has little which parallels the situation in France at the end of the Eighteenth Century or in Germany after the World War. Because Continental currency and Confederate money became worthless is little reason to expect a like fate for the American dollar. While our national debt is large it is not yet disproportionate to our potential productive capacity. We are still rich in natural resources and in facilities for production. The present depression is evidence of the difficulty of starting a boom and of the potency of means for stopping one when it is once started.

A thoughtful settlor will weigh the prospects dispassionately and will order the course of his trustee accordingly. If he wants a streamlined trust able to move swiftly from bonds into stocks, and from stocks into commodities, and from commodities into pounds, or marks, or francs, or yens and then back into dollar bonds, it is within his power so to provide. The trustee, if a satisfactory one can be found, will then take on the aspects of an investment counsel with a speculative tinge. $\mathrm{He}$ may succeed in a large way, or he may fail miserably. If a settlor believes that inflation is just around the corner he may want to take the chance. If he is less sure he will probably do well to hold to first principles, supplemented by some of the devices here suggested.

In this program of making a trust fulfill its function a trustee can do much both through planning with the settlor in advance and through sympathetic administration as the need arises. But the trustee who steps out of his prescribed or accustomed role and volunteers to become the savior of the purchasing power of his trust is embarking upon a course which may prove dangerous to himself and disastrous to the beneficiaries whom he professes to serve. 